\title{
AN EXPERIMENTAL INVESTIGATION ON EXPANSIVE SOIL IN CONJUNCTION WITH EGG SHELL POWDER AND ROCK DUST
}

\author{
Bapiraju P \\ Associate Professor, Department of Civil Engineering, \\ Bapatla Engineering College, Andhra Pradesh, India \\ Nagendra Prasad $K^{*}$ \\ Professor, Department of Civil Engineering, S.V.U. College of Engineering, \\ S.V. University, Tirupati, India \\ *Corresponding Author: kotanp_svu@yahoo.com
}

\begin{abstract}
Expansive soils are problematic due to the presence and consequent effect of their clay mineral constituents, which makes them show the volume change characteristics. The expansive and shrinkage behavior makes expansive soils unsuitable for direct engineering application in their natural form. In an effort to make them more practicable for different engineering applications, various additives and techniques are employed to improve the soil properties. Stabilization of soil with lime, cement, bitumen are expensive and therefore they are in need of an economic replacement. Further, replacement of expansive soils with good quality soil is quite uneconomical. The present investigation considers the effect of Egg Shell Powder (ESP) on expansive soil. The ESP Eggshell is a desecrate material from domestic sources such as poultries, hatcheries, homes and fast food hotels. Proper utilization of the ESP in conjunction with soil, if proved effective, could mitigate environmental pollution to larger extent. The Rock Dust (RD) which is being thought of as alternative to sand in the construction field, has been used, in proportion of 10-30\%, in combination with optimum content of ESP for deriving maximum advantage of improving the engineering characteristics of soil. The sample of expansive clay has been extracted from Emani village of Duggirala Mandal of Tenali revenue division of Andhra Pradesh. The laboratory tests were conducted to find out the effect of these additives on consistency limits, compaction properties and California Bearing Ratio (CBR) at soaked condition. The purpose of the study is essentially to suggest the optimum combination to practicing engineers for use in various reengineering applications
\end{abstract}

Keywords: Soil improvement, Egg Shell Powder (ESP), Quarry Dust (QD), Maximum dry density (MDD), Optimum moisture content (OMC), California bearing ratio test (CBR). 
Cite this Article: Bapiraju P and Nagendra Prasad K, An Experimental Investigation on Expansive Soil in Conjunction with Egg Shell Powder and Rock Dust, International Journal of Advanced Research in Engineering and Technology, 10 (5), 2019, pp 9-21.

http://iaeme.com/Home/issue/IJARET?Volume $=10 \&$ Issue $=5$

\section{INTRODUCTION}

Due to the unfavorable nature of expansive soil, geotechnical engineers are steadily searching for various options to alleviate its objectionable characteristics via soil stabilization techniques. The aim of the engineers in improving of expansive soil is more or less to control the volume change and plasticity or workability characteristics, at the same time significantly improve the strength properties (Soltani et al., 2017). Research that is carried out to improve the properties of expansive soils has resulted in a vast storehouse of technical knowledge available. The information obtained from these repositories seems to be somewhat divergent. Instead of providing well though over solutions, the information available from stabilization investigations may only serve to complicate issues for the construction engineer. . A lot of locally available byproducts and waste materials from different industrial operations have been used in conjunction with expansive soils for suggesting possible methodologies for soil improvement (Chijioke and Donald,2019).

\section{BACKGROUND INFORMATION}

Recently among other wastes that are calcium based and largely generated, specific studies are being carried out on eggshell for its various civil engineering uses. Eggshell had been studied as partial replacement of cement in concrete (Amaral et al,2013), as a fine aggregate in concrete (Raji and Samuel ,2015), as a filler in hot mix asphalt( Erfen and Yunus,2015); as a stabilizing binder for soil improvement (Muthu Kumar and Tamilarasan ,2014). These various engineering applications of eggshell had led to environmental sustainability through the production of a low- cost raw material and waste management. A case study was presented (Oluwatuyia et al 2018 ) outlining the outcomes from the laboratory assessment of a lateritic soil stabilized with milled eggshell, cement and mixture of both in ratio 1:1 for potential use as a highway construction material. The stabilizing binders were added to the soil at proportions of $\mathrm{f} 0,2,4,6$, and $8 \%$ by weight of the soil and afterwards subjected to various laboratory tests to determine its beneficial effect. Egg Shell Powder (ESP) and Quarry Dust (QD) were used (Saji and Mathew, 2016) to study the effect on the properties of clayey soil. An improvement in the strength properties of soil by addition of ESP and QD will help to find an application for waste materials to improve the properties of clayey soil and can be used as a better stabilizing agent. The work (Kavyashree et al, 2016) brings out the effect of lime and eggshell powder on some geotechnical properties of black cotton soil, in order to determine the suitability of lime and eggshell powder for use as a modifier or stabilizer in the treatment of black cotton soil for roadwork.

\section{SCOPE OF STUDY}

The present work is focused on bringing out the possible effect of Egg Shell powder and Quarry dust in conjunction with optimum proportion of Egg Shell Powder on black Expansive soil. 
An Experimental Investigation on Expansive Soil in Conjunction with Egg Shell Powder and Rock Dust

\section{OBJECTIVE OF THE STUDY}

One of the most common methods of fine soil improvement is to stabilize it using additives that improve soil property through physical \& chemical changes. In the view of the aforementioned discussion, the following may be stated as objectives of the present study.

- To study the effect of Egg Shell Powder and Rock Dust on basic properties of soil such as liquid limit, plastic limit, plasticity index which indicate the engineering behavior of soils

- To study the effect of Egg shell Powder and Rock Dust on Compaction Characteristics of Soils

- To study the effect of Egg Shell Powder and Rock Dust on California Bearing Ratio

- To propose possible optimum combination and further scope of the study

\section{MATERIALS AND METHODS}

\subsection{Expansive soil}

The soil used in this study is an expansive soil (Black cotton soil) collected from Emani village, Duggirala Mandal of Tenali revenue division, Andhra Pradesh. The soil was collected by the method of disturbed sampling after removing the soil cover over an extent of about $500 \mathrm{~mm}$. The general chemical composition of the soil tested is presented in Table 1

Table 1 Chemical Composition of Expansive Soil

\begin{tabular}{|c|c|c|}
\hline S.No & Description & Range \\
\hline 1 & Silica(SiO2) & $45-58 \%$ \\
\hline 2 & Alumina(A12O3) & $13-22 \%$ \\
\hline 3 & Lime(Ca(OH)2) & $1-8 \%$ \\
\hline 4 & Magnesium oxide(MgO) & $1.8-5 \%$ \\
\hline 5 & Ferric oxide (Fe2O3) & $7.5-15 \%$ \\
\hline 6 & Sulphates (SO4-2) & $0.9-2.0 \%$ \\
\hline 7 & Carbonates (CO3-2) & $0.5-6.6 \%$ \\
\hline 8 & Organic matter & $0.54-3.6 \%$ \\
\hline 9 & Loss of ignition & $4.86-16.5 \%$ \\
\hline 10 & PH & $6.7-8.9 \%$ \\
\hline
\end{tabular}

The tests have been conducted (Table 2) on soil samples obtained from the field. All tests have been conducted as per the relevant provisions stipulated in respective IS code procedures.

Table 2 : Tests Conducted

\begin{tabular}{|c|c|}
\hline Test Conducted & IS code of Practice \\
\hline Liquid Limit & IS $2720-5: 1985$ \\
\hline Plastic Limit & IS : 2720 (Part III/Sec 1-1980 \\
\hline Specific Gravity & IS 2720-7:1980 \\
\hline Maximum Dry Density & IS 2720-16:1991 \\
\hline Optimum Moisture Content & \\
\hline CBR TEST & \\
\hline
\end{tabular}




\subsection{Egg Shell Powder}

Eggshell is a unique, cost-effective, environment friendly technological innovation in soil improvement. Egg Shell Powder is a unique and highly efficient natural inorganic soil stabilizer for use in road construction and repair. It meets the requirement for a well-proven, dependable and very economical method for creating strong and irretrievable impermeable layer resistant to adverse climatic conditions, from very high temperatures to cold climatic conditions, and accommodating all types of roads and load requirements. It is ecological friendly and highlights the use of recycled material, recognizing the lack of readily available resources. It reduces the Carbon Footprint of any project by reducing transportation requirements and carbon emissions.

An eggshell is the outer covering of a hard-shelled egg and of some forms of eggs with soft outer coats. Eggshell is made almost entirely of calcium carbonate $(\mathrm{CaCO} 3)$ crystals. It is a semi porous membrane, which means that air and moisture can pass through its pores. The shell also has a thin outermost coating called the bloom that glues the dust.

Eggshell powder (ESP) has not been fully explored despite sporadic studies exist highlighting its utilization in civil engineering applications as a stabilizing material and it could be a good replacement for industrial lime, since its chemical composition is similar to that of lime. Literature has shown that eggshell powder primarily contains $\mathrm{CaO}(99.83 \%)$ and the remaining consists of $\mathrm{Al} 2 \mathrm{O} 3, \mathrm{SiO} 2, \mathrm{MgO}, \mathrm{CaCO} 3, \mathrm{SO} 3, \mathrm{Na} 2 \mathrm{O}, \mathrm{Ca} 2$ and $\mathrm{Fe} 2 \mathrm{O} 3$. The eggshell waste was washed and dried before grinding. This was kept in the hot air oven for drying at $900^{\circ} \mathrm{C}$ for 3 hours of heating. The dried eggshell powder was powered and sieved to $425 \mu$. The specific gravity of eggshell Powder is 2.09.The chemical composition of the Egg shell Powder is given in Table 3.

Table 3: Chemical composition of Egg Shell Powder

\begin{tabular}{|c|c|c|}
\hline S.No & Description & Range \\
\hline 1 & Calcium Oxide $(\mathrm{CaO})$ & $>73.3 \%$ \\
\hline 2 & Magnesium Oxide & $<0.5 \%$ \\
\hline 3 & Silicon Dioxide & $<2 \%$ \\
\hline 4 & Alumina Trioxide & $<1.5 \%$ \\
\hline 5 & Ferric trioxide $\left(\mathrm{Fe}_{2} \mathrm{O}_{3}\right)$ & $<2.5 \%$ \\
\hline 6 & Sulphate Trioxide $\left(\mathrm{SO}_{3}\right)$ & $<0.5 \%$ \\
\hline 7 & Carbon Dioxide $\left(\mathrm{CO}_{2}\right)$ & $0.4-0.5 \%$ \\
\hline 8 & Calcium Tricarbonate $\left(\mathrm{CaCO}_{3}\right)$ & $<5.0 \%$ \\
\hline 9 & Sodium Oxide $\left(\mathrm{NA}_{2} \mathrm{O}\right)$ & $<100 \%$ \\
\hline
\end{tabular}

\subsection{Rock Dust}

Quarry dust/crusher dust is obtained as soil solid wastes during crushing of stones to obtain aggregates. Quarry dust exhibits high shear strength which is highly beneficial for its use as a geotechnical material. It has a good permeability and variation in water content does not seriously affect its strength properties. Quarry dust proved to be a promising substitute for sand and can be used to improve the engineering properties of soils. The dry density increased with the addition of quarry dust with the attendant decrease in the optimum moisture content. It was sieved through BIS sieve number $4.75 \mu$ and then stored for further investigations. Its specific gravity is 2.65 . The chemical composition of the dust is presented in Table 4 . 
An Experimental Investigation on Expansive Soil in Conjunction with Egg Shell Powder and Rock Dust

Table 4: Chemical composition of rock dust

\begin{tabular}{|c|c|c|}
\hline S.No & Description & Range \\
\hline 1 & Calcium Oxide $(\mathrm{CaO})$ & $5-10 \%$ \\
\hline 2 & Magnesium Oxide & $<10 \%$ \\
\hline 3 & Silicon Dioxide & $60-65 \%$ \\
\hline 4 & Alumina Trioxide & $15-20 \%$ \\
\hline 5 & Ferric trioxide $\left(\mathrm{Fe}_{2} \mathrm{O}_{3}\right)$ & $5-10 \%$ \\
\hline 6 & Sulphate Trioxide $\left(\mathrm{SO}_{3}\right)$ & $<0.5 \%$ \\
\hline 7 & Potassium Oxide $\left(\mathrm{K}_{2} \mathrm{O}\right)$ & $0.4-0.5 \%$ \\
\hline 8 & Sodium Oxide $\left(\mathrm{NA}_{2} \mathrm{O}\right)$ & $<100 \%$ \\
\hline
\end{tabular}

\section{ANALYSIS OF TEST RESULTS}

Any soil whose volume changes are sensitive to moisture content is considered as expansive soil. Expansive soils are identified as difficult soils owing to their potential to affect the stability of structures founded on them. Consequently, it becomes very crucial for a practicing geotechnical engineer to properly identify and characterize such soils. This in turn will help in material management, which is an essential component of any project execution.

The inferential testing methods try to link some of the index properties of fine-grained soils with the soil clay mineralogical composition and hence, to estimate their swell potential (Sridharan and Prakash, 2016). They can be classified as indirect methods and direct methods. Indirect methods make use of soil index properties such as liquid limit, shrinkage limit, percent clay size composition of soils and also some of the indices such as plasticity index, shrinkage index and the like to estimate the swell potential of soils. Different schemes are available to recognize the soil expansively based on the plasticity index of the soils, one such scheme proposed in IS 1498-1970 is presented in Table 5. Black cotton soils are inorganic clays of medium to high compressibility and form a major soil group in India. They are predominantly montmorillonite in structure and black or blackish grey in color. They are characterized by high shrinkage and swelling properties. The majority of the soils, when plotted on the plasticity chart, lie along a band above the ' $A$ ' line Fine grained soils depending upon the presence of clay mineral exhibit low to very high degree of expansion. Based upon Atterberg limits and free swell of the soils the degree of expansion and degree of severity for soils is given in IS: 1498-1970; Table 8, which id reproduced as

Table 5: Degree of Expansion of fine Grained Soils (as per IS 1498-1970)

\begin{tabular}{|c|c|c|c|}
\hline Liquid Limit ,LL:\% & Plasticity Index, PI:\% & Shrinkage Index, \% & Degree of Expansion \\
\hline $20-35$ & $<12$ & $<15$ & Low \\
\hline $35-50$ & $12-23$ & $15-30$ & Medium \\
\hline $50-70$ & $23-32$ & $30-60$ & High \\
\hline $70-90$ & $>32$ & $? 60$ & Very High \\
\hline
\end{tabular}

Liquid limit: This upper bound plasticity limit is determined in the laboratory by the conventional Casagrande method or by the fall cone method. Liquid limit of a soil is considered as water holding capacity of the soil, which in turn has been taken as a measure of soil swell potential. Many classification schemes are available in the geotechnical engineering literature to recognize the degree of soil swell potential based on the liquid limit of finegrained soils. Plasticity Index: It is the difference between the liquid limit and plastic limit of 
fine-grained soils. Higher the plasticity index, more plastic the soil is and higher will be the soil swell potential.

The properties of black cotton considered in the present investigation are presented in Table 6. It may be observed that the Liquid Lint of soil is $60 \%$, plastic limit is $30 \%$ and shrinkage limit is $14 \%$. The plasticity index of $30 \%$ is indicative of the expansive nature of the soil and shrinkage limit is as low as $14 \%$ turns out that upon drying the soil would undergo large volume changes. The properties are typical of the high volume change behavior of expansive soil. The optimum moisture content is 0.80 times the plastic limit, which indicates that the soil is absorbing high water content for reaching maximum dry density. The value of CBR is as low as 1.12 indicating low penetration resistance of the soil under soaking. Such soils are difficult which need stabilization when encountered in practice during any engineering construction process.

Table 6 Basic Soil Properties

\begin{tabular}{|c|c|}
\hline Description & Value \\
\hline Natural moisture content, $\%$ & 40 \\
\hline Specific Gravity & 2.38 \\
\hline Liquid Limit, $\%$ & 60 \\
\hline Plastic Limit, $\%$ & 30 \\
\hline Plasticity Index, $\%$ & 30 \\
\hline Shrinkage Limit, $\%$ & 14 \\
\hline Optimum Moisture Content, $\%$ & 24 \\
\hline Maximum Dry Density, $\mathrm{kN} / \mathrm{m}^{3}$ & 17.70 \\
\hline California Bearing Ratio, $\%$ & 1.12 \\
\hline
\end{tabular}

\subsection{Effect of Egg Shell Powder (ESP) on Consistency Limits}

\subsubsection{Liquid Limit}

As the water content of soil is raised its strength falls, the soil would become weak and flows like liquid and it represents the water holding capacity. The Figure 1 Shows the variation of Atterberg limits with addition of Egg Shell Powder. The liquid limit is reducing rapidly up to $4 \%$ and then rate of decrease is falling. The mechanisms governing the behavior could be one of the following:

- The Base Exchange Capacity may be more active owing to chemical composition of Egg Shell Powder, satisfying the negative charge and resulting in release of held water.

- After the initial Base Exchange Capacity the additional Egg Shell Powder may be going into solution causing no effect, whatsoever.

- Porous nature of the Egg Shell Powder may affect the water retention adversely

\subsubsection{Plastic Limit}

As the water content is reduced, the soil strengthens owing to increase in inter particle resistance making the soil relatively strong indicating increase in shear strength. It may be observed from the Figure 1 that the plastic limit value is increasing with addition of Egg Shell Powder. The mechanisms governing the behavior may be sted as follows:

- The Egg Shell Powder reduces the water imbibing process on account of Base Exchange Capacity and resulting in imparting structural resistance and hence shears strength of the soil. 
An Experimental Investigation on Expansive Soil in Conjunction with Egg Shell Powder and Rock Dust

- The Egg Shell Powder continuously contribute to structural resistance because the surface area being less having more porous and roughness leading to incrase in shear strength.

\subsubsection{Plasticity Index}

Plasticity Index represents the range over which the given soil remains plastic. With the introduction of Egg Shell Powder the water holding capacity reduces and structural resistance increases and hence resulting in reduction in Plasticity Characteristics. It may be seen from the Figure 1 that the plasticity index reduces continuously with the addition of Egg Shell Powder. Further, with reference to Table 4 , the Swell potential as indicated by Plasticity index initially has reduced from high potential $(30 \%)$ to low potential (12\%) at $4 \%$ Egg Shell Powder.

\subsubsection{Compaction Characteristics}

The importance of compaction as a realistic method to control strength, compressibility and permeability properties of soils has been amply confirmed by the fact that it is in use since the time when early earth structures were built. Every day, millions of cubic meters of soils are compacted all over the world since the compaction is the only simple viable means of effecting marked changes in engineering properties of soils cost-effectively. Properly positioned and compacted soil mass has the strength and stability that are as good as or even better than many natural formations. Compaction is the simple method of densification by exclusion of air voids using mechanical manipulation. Compaction of soil at maximum dry density is essential in many engineering projects. The moisture content dry density relationship of the soil obtained from laboratory tests forms the basis for specification and field compaction control.

\subsection{Effect of ESP on Compaction Characteristics}

The effect of ESP on compaction cures are presented in Figures 2-3. It may be noticed that with increase in proportion of ESP the dry density increases up to certain percentage and then follows recession. The mechanisms governing the observed behavior are same as presented before for the consistency limits. The absorbed water is dispelled enabling the particles to attain closer configuration with initial percentages and the addition of excess ESP may result in dilution phenomenon, causing dispersion effect.

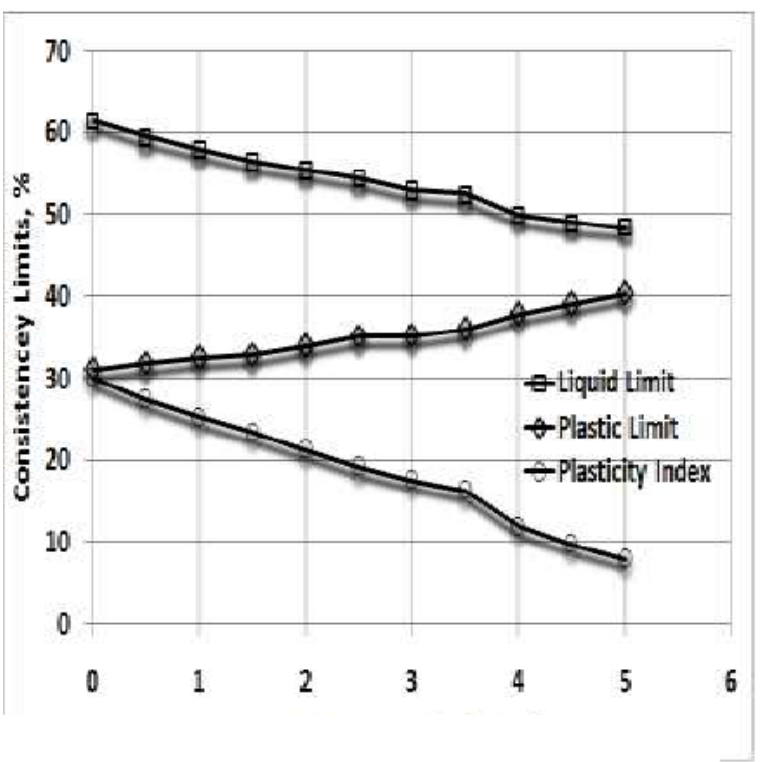

Figure 1: Effect of Egg Shell Powder on Consistency limits

http://iaeme.com/Home/journal/IJARET

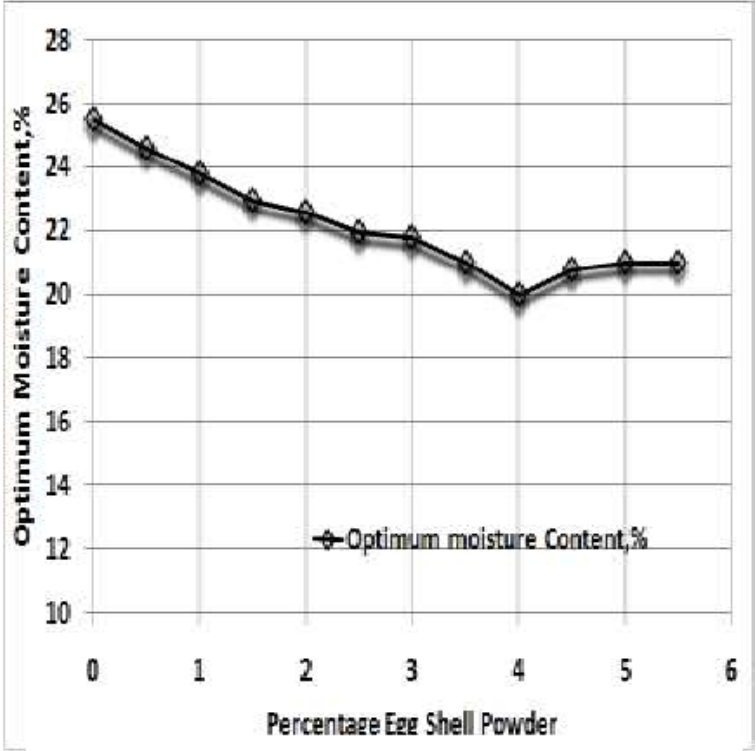

Figure 2: Effect of Egg Shell Powder on Optimum moisture content 


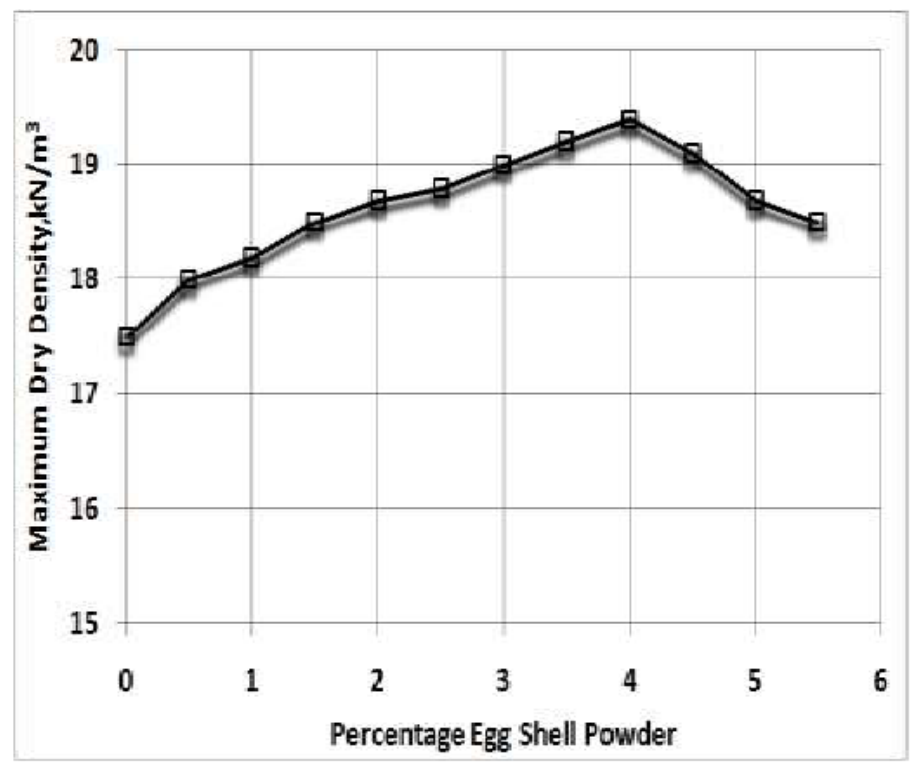

Figure 3: Effect of Egg Shell Powder on dry density

\subsection{Effect of Rock Dust (RD) on Consistency Limits}

Black cotton soils s are often unsuitable for direct engineering application in their natural form. In an attempt to make them more appropriate for construction purposes, numerous materials and techniques are used to stabilize the soil (Chijioke and Donald,2019). One of the sustainable material is rock dust, which a byproduct of quarry industry and results from rock crushing. If proved effective, use of rock dust may mitigate pollution aspects and could become resource material as well.

Accordingly, this experimental investigation considers tock dust in proportions of 10-30 for determining its effect on basic and strength characteristics. The effect of rock dust on consistency limits is shown in Figure 4. It may be seen that the liquid limit, plastic limit and plasticity index gradually decrease with the addition of rock dust. Addition of rock dust may contribute to dilution phenomenon and the water holding capacity of soil decreases. Addition of 4\% optimum ESP further decrease the liquid limit, plastic limit and plasticity index which proves that addition of optimum content of ESP is more effective in the stabilization process.

\subsection{Effect of Rock Dust (RD) on Compaction Characteristics}

An attempt has been made to determine the effect of Rock Dust on compaction characteristics. The variation in compaction characterizes are shown in figure 5-6. It may be noticed that the effect of rick dust is to increase the dry density over proportions of the rock dust considered. Further, the optimum moisture content gradually decreases. The reasons may be attributed to the fact that the rock dust, having greater specific weight than the soil may contribute to increase in dry density value. The rock dust possess lower specific surface and hence requirement of water to cause mobility of the soil particles in the densification process may be less. Hence a continuous decrease is noticed in the test results.

An attempt also has been made to further examine the effect or rock dust in combination of optimum ESP content of 4\%. The test results are shown in Figures 5-6. It may be noticed that the rock dust with combination of optimum ESP is proving to be more effective with increase in dry density and decrease in optimum moisture content values.

The mechanisms governing the behavior may be stated as follows: 
- Rock dust with greater specific weight is contributing to higher densities. In addition, the optimum Egg Shell Powder content 4\% participating in Base Exchange Capacity, satisfying the negative charge of the interacting soil may facilitate the easy movement of the particles in the densification process resulting in higher den sites.

- The rock dust possess lower specific surface and hence requirement of water to cause mobility of the soil particles in the densification process may be less and it may further add to the effect of optimum Egg Shell Powder.

California Bearing Ratio (CBR) - The ratio expressed in percentage of force per unit area required to penetrate a soil mass with a circular plunger of $50 \mathrm{~mm}$ diameter at the rate of 1.25 $\mathrm{mm} / \mathrm{min}$ to that required for corresponding penetration in a standard material. The ratio is usually determined for penetration of $2^{\prime} 5$ and $5 \mathrm{~mm}$. Where the ratio at $5 \mathrm{~mm}$ is consistently higher than that at $2,5 \mathrm{~mm}$, the ratio at $5 \mathrm{~mm}$ is used. The CBR value of a soil can thus be considered to be an index which in some fashion is related to its strength. The value is highly dependent on the condition of the material at the time of testing ( IS: 2720-Part-16). In the present investigation soaked condition is used for determination of CBR.

The variation of CBR with the addition of optimum ESP has been examined as the Compaction density with percentage of ESP has proved to be effective at $4 \%$. The Test Results are shown in Figure 7. It may be observed that the CBR value increases steadily with the addition of quarry dust in combination with optimum ESP. The value of SBR for soil alone is as low as 1.25 and with $30 \%$ rock dust with optimum ESP has resulted in a BR value of 12.5 with an increase in value by 10 times. Depending on the value of CBR required based on traffic condition and type of soil the quantity of rock dust and ESP can be used for from economical point of view. This may be due to the fact that the structural resistance increases at particle level with the addition of rock dust with optimum ESP resulting in enhanced CBR .

\subsection{Expansion ratio}

It is a test for swelling as prescribed in IS: 2720-Part 16. The expansion ratio is used to qualitatively identify the potential expansiveness of the soil

A filter paper shall be placed over the specimen and the adjustable stem and perforated plate shall be placed on the compacted soil specimen in the mould. Weights to produce a surcharge equal to the weight of base material and pavement to the nearest $2.5 \mathrm{~kg}$ shall be placed on the compact soil specimen. The whole mould and weights shall be immersed in a tank of water allowing free access of water to the top and bottom of the specimen. The tripod for the expansion measuring device shall be mounted on the edge of the mould and the initial dial gauge reading recorded. This set-up shall be kept undisturbed for 96 hours noting down the readings every day against the time of reading. A constant water level shall be maintained in the tank through-out the period.

Expansion Ratio - The expansion ratio based on tests conducted as specified in ( IS:2720Part-16) shall be calculated as follows:

Where,

$$
\text { Expansion ratio }=\frac{d_{f}-d_{s}}{h} X 100
$$

$\mathrm{d}_{\mathrm{f}}=$ final dial gauge reading in $\mathrm{mm}$,

$\mathrm{d}_{\mathrm{s}}=$ initial dial gauge reading in $\mathrm{mm}$, and

$\mathrm{h}=$ initial height of the specimen in $\mathrm{mm}$. 
The variation of Expansion ratio with addition of rock dust with optimum ESP is presented in Figure 8. It may be seen that the expansion ratio decreases from a value of 7 to 1.17 which is a significant decrease in expansion potential.

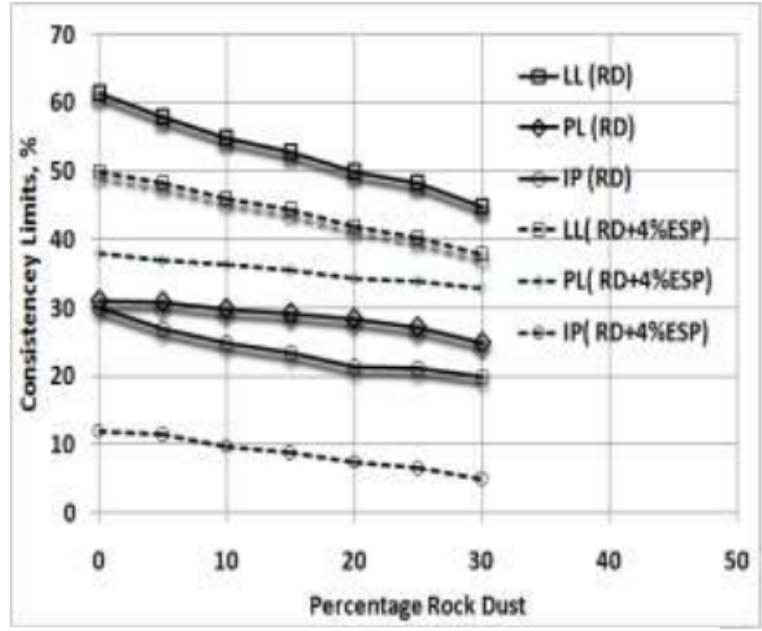

Figure 4: Effect of Rock Dust and Rock Dust with optimum ESP on consistency limits

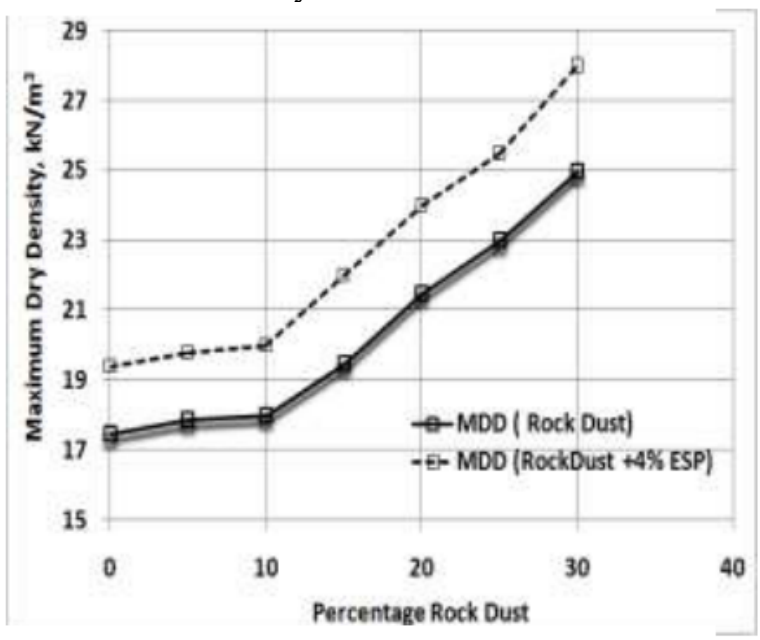

Figure 6: Effect of Rock Dust and Rock Dust with optimum ESP

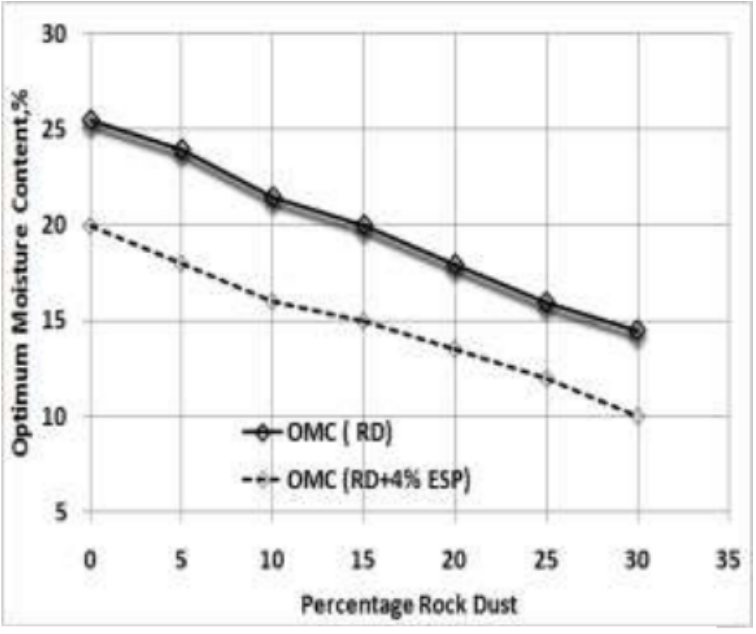

Figure 5: Effect of Rock Dust and Rock Dust with optimum ESP on optimum moisture content

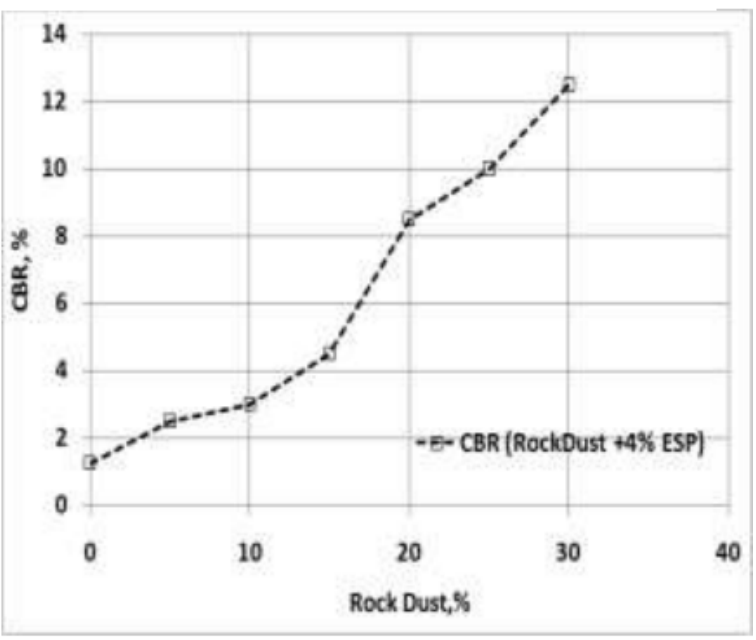

Figure 7: Effect of Rock Dust and Rock Dust with optimum ESP on CBR

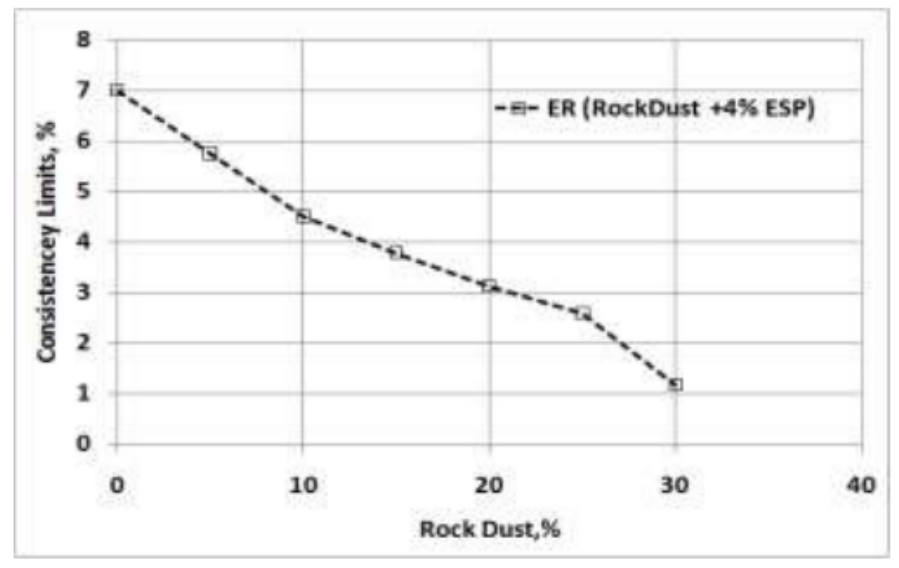

Figure 8 Effect of Rock Dust and Rock Dust with optimum ESP on expansion ratio 
An Experimental Investigation on Expansive Soil in Conjunction with Egg Shell Powder and Rock Dust

\section{CONCLUDING REMARKS}

Based on limited experimental program and analysis of the Test Results the following concluding remarks may be made:

\subsection{Effect of Egg Shell Powder (ESP) on Consistency Limits}

\subsubsection{Liquid Limit}

The liquid limit is reduces steadily up to $4 \%$ and then rate of decrease is falling. The mechanisms governing the behavior could be one of the following:

- The Base Exchange Capacity may be more active owing to chemical composition of Egg Shell Powder, satisfying the negative charge and resulting in release of held water.

- After the initial Base Exchange Capacity the additional Egg Shell Powder may be going into solution causing no effect, whatsoever.

- Porous nature of the Egg Shell Powder may affect the water retention adversely

\subsubsection{Plastic Limit}

The plastic limit value increases with addition of Egg Shell Powder. The mechanisms governing the behavior may be stated as follows:

- The Egg Shell Powder reduces the water imbibing process on account of Base Exchange Capacity and resulting in imparting structural resistance and hence shears strength of the soil.

- The Egg Shell Powder continuously contribute to structural resistance because the surface area being less having more porous and roughness leading to incrase in shear strength.

\subsection{Effect of ESP on Compaction Characteristics}

The effect of ESP on compaction cures is to increase the dry density up to certain percentage and then follows recession. The mechanisms governing the observed behavior are same as presented before for the consistency limits. The absorbed water is dispelled enabling the particles to attain closer configuration with initial percentages and the addition of excess ESP may result in dilution phenomenon, causing dispersion effect.

\subsection{Effect of Rock Dust (RD) on Compaction Characteristics}

The effect of rick dust is to increase the dry density over proportions of the rock dust considered. Further, the optimum moisture content gradually decreases. The reasons for the observed behavior may be stated as:

- The rock dust, having greater specific weight than the soil may contribute to increase in dry density value.

- The rock dust possess lower specific surface and hence requirement of water to cause mobility of the soil particles in the densification process may be less. Hence a continuous decrease is noticed in the test results.

\subsection{Effect of Rock Dust (RD) with Optimu percentage of ESP on Compaction Characteristics}

The rock dust with combination of optimum ESP is proving to be more effective with increase in dry density and decrease in optimum moisture content values. The mechanisms governing the behavior may be stated as follows: 
- Rock dust with greater specific weight is contributing to higher densities. In addition, the optimum Egg Shell Powder content 4\% participating in Base Exchange Capacity, satisfying the negative charge of the interacting soil may facilitate the easy movement of the particles in the densification process resulting in higher den sites.

- The rock dust possess lower specific surface and hence requirement of water to cause mobility of the soil particles in the densification process may be less and it may further add to the effect of optimum Egg Shell Powder.

\subsection{Effect of Rock Dust (RD) with Optimum percentage of ESP on California Bearing Ratio (CBR)}

The variation of CBR with the addition of optimum ESP has been examined as the Compaction density with percentage of ESP has proved to be effective at $4 \%$.

- The value of SBR for soil alone is as low as 1.25 and with $30 \%$ rock dust with optimum ESP has resulted in a BR value of 12.5 with an increase in value by 10 times. This may be due to the fact that the structural resistance increases at particle level with the addition of rock dust with optimum ESP resulting in enhanced CBR .

Depending on the value of CBR required based on traffic condition and type of soil the quantity of rock dust and ESP can be used for from economical point of view.

\subsection{Effect on Expansion ratio}

- The expansion ratio decreases from a value of 7 to 1.17 which is a significant decrease in expansion potential.

\section{FUTURE SCOPE OF WORK}

Despite limitation of the experimental program undertaken in the present investigation, the test results are indicative of the fact that the use of ESP up to a certain percentage is quite effective in improving the expansive soil characteristics. Further, Use of rock dust in combination with optimum ESP would be even more effective. To further reinforce the observation and to suggest a comprehensive framework for practicing engineers dealing with such soils, more number of soils with varying expansive potentials can be considered in conjunction with ESP and rock dust.

\section{REFERENCES}

[1] Amaral, M.C., Siqueira, F.B., Destefani, A.Z. and Holanda, J.N.F, Soil - cement bricks incorporated with eggshell waste, Proc. Inst. Civ. Eng. Waste Resour. Manag. 166 (2013) 137-141, doi:http://dx.doi.org/10.1680/warm.12.00024.

[2] Chijioke Christopher Ikeagwuani, Donald Chimobi Nwonu ,'Emerging trends in expansive soil stabilization: A review', Journal of Rock Mechanics and Geotechnical Engineering journal homepage: www.rockgeotech.org Journal of Rock Mechanics and Geotechnical Engineering 11 (2019) PP 423-440

[3] Erfen, Y.B. and Yunus, K.N.B.M, the Appropriateness of Egg Shell as Filler in Hot Mix Asphalt, (2015), pp. 1-9.

[4] Geethu Saji1, Nimisha Mathew, 'Improvement Of Clayey Soil By Using Egg Shell Powder And Quarry Dust', IOSR Journal of Mechanical and Civil Engineering (IOSR-JMCE) , 2016, PP 46-54

[5] Dr. Ch. Kannam Naidu, Dr. Ch. Vasudeva Rao, Dr. G. Venkata Rao and A.Y.D.T. Akhilesh, Experimental Study On M30 Grade Concrete With Partial Replacement Of Cement With Egg Shell Powder, International Journal of Civil Engineering and Technology, 9(5), 2018, pp. $575-583$. 
An Experimental Investigation on Expansive Soil in Conjunction with Egg Shell Powder and Rock Dust

[6] Kavyashree M.P, Renukaprasad M.S, Maruti Rama Naik,' Black Cotton Soil Stabilization Using Eggshell Powder and Lime', IJSART - Volume 2 Issue 10 -OCTOBER 2016, Page 1-8

[7] Muthu Kumar, M. and Tamilarasan, V.S, Effect of eggshell powder in the index and engineering properties of soil, Int. J. Eng. Trends Technol. 11 (2014) 319-321.

[8] N. Vijay Kumar, SS.Asadi and A.V.S. Prasad, Estimation of Bearing Capacity of Black Cotton Soil Using Rock Dust and Geo-Textile Sheet: An Experimental Study, International Journal of Mechanical Engineering and Technology 8(10), 2017, pp. 886-895.

[9] Opeyemi E. Oluwatuyia,, Bamidele O. Adeolaa, Elijah A. Alhassanb, Emeka S. Nnochiric, Abayomi E. Modupea, Olugbenga O. Elemilea, Temidayo Obayanjua, Grace Akerelea, 'Ameliorating effect of milled eggshell on cement stabilized lateritic soil for highway construction', Case Studies in Construction Materilas, Elsevier publication,2018, PP 1-9

[10] Raji, S.A. and Samuel, A.T, Egg shell as a fine aggregate in concrete for sustainable construction, Int. J. Sci. Technol. Res. 4 (2015) 8-13.

[11] Soltani A, Taheri A, Khatibi M, Estabragh AR, 'Swelling potential of a stabilized expansive soil: a comparative experimental study', Geotechnical and Geological Engineering; 35(4), 2017, pp 1717-44.

[12] Madan Mohan Reddy. K, Sivaramulu Naidu. D, Sanjeeva Rayudu. E, Studies on Recycled Aggregate Concrete by Using Local Quarry Dust and Recycled Aggregates, International Journal of Civil Engineering and Technology (IJCIET).Volume:3, Issue: 2, 2012, Pages: 322326.

[13] G.Karthikeyan, Study of Self Compacting Concrete with Partial Replacement of Sand by Quarry Dust, International Journal of Civil Engineering and Technology (IJCIET).Volume: 8, Issue: 7, 2017, Pages: 1177-1187.

[14] Sridharan Asuri and Prakash Keshavamurthy, 'Expansive Soil Characterization: an appraisal', INAEL (2016), pp 1:29-33,DOI 10.1007/s41403-016-0001-9

[15] Vetriselvan M and Senthamilkumar S, Study on High Performance Concrete Beam Under Cyclic Loading Conditions by Partial Replacement of Fly Ash and Quarry Dust. International Journal of Civil Engineering and Technology, 8(12), 2017, pp. 1098-1106

[16] Indian Standard Method of Test for Soils-Determination of Liquid Limit and Plastic Limit, IS:2720

[17] Vetriselvan. M and Senthamilkumar. S, Study on Structural Properties of Concrete by Partial Replacement of Fly Ash and Quarry Dust, International Journal of Civil Engineering and Technology, 9(8), 2018, pp. 621-626.

[18] Indian Standard Method of Test for Soils-Determination of Specific Gravity, IS:2720

[19] Indian Standard Method of Test for Soils-Determination of Water Content-Dry Density Relation using light compaction, IS:2720

[20] Indian Standard Method of Test for Soils- Laboratory Determination of CBR, IS:2720 (Indian Standard Classification of Soils for General Engineering Purposes, IS:1498-1970 